\title{
Nonstationary separation of Nd and Pr by P507 extractant
}

\author{
V.A. Dorozhko, M.A. Afonin
}

Department of technology of rare elements and nanomaterials, Saint-Petersburg State Institute of Technology, Saint-Petersburg, Russia

\begin{abstract}
The low efficiency of the separation of rare earth metals by extraction on one stage requires the combination of a large number of mixer-settlers in a cascade. The problem of increasing the rare earth elements separation factor is extremely urgent. One of the perspective methods is the nonequilibrium nonstationary process. In this work, it is offered to use the principle of a nonstationary extraction in the separation process of the $\mathrm{Nd} / \mathrm{Pr}$ pair from chloride medium by the extractant based onP507. The results which have been received by an experimental setup allowing the monitoring of the influence of a cyclic change of physicalchemical parameters on extraction in the online modeare discussed. A comparison of two ways of implementation of extraction in the nonstationary mode is carried out. The apparent values of physicalchemical parameters $(\Delta \mathrm{G}, \Delta \mathrm{H}, \Delta \mathrm{S})$ in the temperatures range $15-65^{\circ} \mathrm{C}$ are calculated from the data of joint extraction of $\mathrm{Nd}$ and $\mathrm{Pr}$.
\end{abstract}

\section{INTRODUCTION}

The cascades for obtaining the individual rare earth metals can consolidate up to 150 apparats. To obtain individual metals of the purity, required by modern industry from a natural mixture containing $\mathrm{n}$ components, $2 \mathrm{n}-1$ cascades are needed, which, on average, combine the same numbers of stages [1]. Due to it, the separation factory has a high capital cost. It limits the creation of new separation capacities. [2] presented the specification of technologies of producing of purity rare earth metals from the natural and technogenic raw materials, which are applied in China. Achievements of the global rare metal industry are presented in the monograph of [3]. In the work of [4], the state and prospects of recovery and development of the REM industry in Russia are studied.

At Saint-Petersburg Mining University, in collaboration with the PhosAgro Company, some works are being carried out to create a technology of group concentrates or individual REMsproduction in the process of complex processing of the Kola apatite concentrate. [5] described the technology for the complex processing of phosphogypsum, which is - waste from the production of phosphoric acid, including the associated production of a concentrate of rare earth metals. [6] described fundamental principles of the associated extraction of REMs by DEHPA from industrial solutions of phosphoric acid. In the paper of [7] the benchmark of the kinetics and technological characteristics of REM extraction from phosphoric acid media by the DEHPA solution and a solid-phase extraction agent "Levextrel" containing DEHPA was carried out. In [8], the conditions for the extraction 
concentration of heavy rare earth elements contained in the apatite raw materials were determined [9] studied the scrubbing of an extract of DEHPA, containing REMs from impurity elements, at the stage of stripping.

The multitude of extractors in a cascade was obtained due to the small efficiency of each separation stage. The similar chemical properties of f-elements do not allow developing effective schemes of separation, based on extraction, by different solvents. 2ethylhexyl phosphonic acid mono-2-ethylhexyl ether (PC88A, HEHEHP, EHPNA, P507), is a commercial extractor that has shown the highest efficiency in the separation of REE in the chloride media; in the last 15 years, it shifted out the classical TBP and D2EHPA from the technology of production of individual rare earth metals of the light group [10].

Now, the problem of finding solutions to increase the separation factor $(\beta)$ of a pair of elements in the extraction process is quite acute. There is a technology [11] which is the most effective scheme of separating the light group of REMs in the conventional cascade process. An effective separation was achieved by applying 1,5 M PC88A in combination with the reflux technology. In the report of a company [12] the RapidSX ${ }^{\mathrm{TM}}$ technology was proposed, in which the cascade of mixer-settlers was replaced by a battery of column-type apparatus. According to the company, this will reduce the volumes of circulating liquids, which will make the separation manufactory cheap and compact.

The direction of extraction by ionic liquids, which is actively developing in Japan, tried to revise the existing separation process. [13] studied selective isolation of $\mathrm{Nd}$, Pr and Dy from aqueous solutions by TODGA, which diluted in the trimethylpentyl phosphonium bis (trifluoromethylsulfonyl) amide ([P2225][TFSA]). This method shows high values of the separation factor but needs large amounts of expensive extractants and accompanying reagents. Because of this, it is unlikely that it will soon become widespread. Besides, for real application in the industry, it is very important to use the industry-approved technologies and commercial substances.

In the recent decade, there appeared works dedicated to the methods of the separation of elements which used nonstationary processes based on the differences in the kinetics of chemical reactions. Now [14] is studying the mechanism of the kinetics of the interphase transfer in extraction processes. In [15], high efficiency of a nonstationary process for the separation of rare earth metals is shown and compared with it under the equilibrium conditions. In [16], an increase in the separation factor of the $\mathrm{Nd} /$ Prpair under nonstationary conditions by TBP liquid membrane from a nitric media is described using periodic temperature oscillations in the extractor.

In this paper, the implementation of nonstationary extraction Principia in the process of separation of the $\mathrm{Nd} / \mathrm{Pr}$ pair in the chloride media by an extractant based on P507 is proposed. The isopar-1 $1^{\mathrm{TM}}$ is a commercially available iso-paraphine of high purity used as a diluent to reduce the effect of impurities on the properties of the extractant. We used the 5\% (vol.) TBP additive as a modifying agent to increase the aggregated stability of the system. The purpose of this work is to consider the general patterns of behavior of the extraction system when the non-stationary conditions are provided in it. The obtained experimental data will be valid for the separation of all REEs; the $\mathrm{Pr} / \mathrm{Nd}$ pair was chosen as an imitation of didymium concentrate, which is used to produce pure $\mathrm{Nd}$.

\section{Preparation of the extractant based on p507 and the aqueous solution of $\mathrm{pr}$ and $\mathrm{nd}$ chlorides}

The extractant was prepared as follows: 2-ethylhexyl phosphonic acid mono-2-ethylhexyl ether (P507) (Shanghai Fopol Chem-Tech Industry Co, China) was diluted in isopar-1 (Exxon Mobil, USA. Liquid isoparaffin of fraction $\mathrm{C}_{11}-\mathrm{C}_{12}$ ) and TBP mixture (volume ratio 9:1). The stock solution, which contains 50\% (mass.) P507, was prepared. The extractant 
was saponified up to $30-35 \%$ (mol.). The saponification degree and concentration of P507 in extractant was measured by basic potentiometric titration in acetone.

The initial solution of chlorides of praseodymium and neodymium was prepared from corresponding oxides $\operatorname{Pr}_{6} \mathrm{O}_{11}$ and $\mathrm{Nd}_{2} \mathrm{O}_{3}$ (qualification "pur."), which were dissolved in concentrated hydrochloric acid (qualification "puriss."). The concentrations of metals and $\mathrm{H}^{+}$were determined by the titrimetry method. The density of solutions was determined by the pycnometer method.

The mixed solution of $\mathrm{Pr}^{3+}$ and $\mathrm{Nd}^{3+}$ with an equimolar concentration of $0.150 \pm 0.005 \mathrm{~mol} / \mathrm{dm}^{3}$ was prepared by mixing of the needed amount of stock solutions of $\mathrm{PrCl}_{3}$ and $\mathrm{NdCl}_{3}$ by weight method in a volumetric flask. Crystal $\mathrm{NaOH}$ (qualification "puriss") was added to reduce $\mathrm{H}^{+}$concentration to the value $\approx 0.03 \mathrm{~mol} / \mathrm{dm}^{3}\left(\mathrm{pC}_{\mathrm{H}^{+}}\right.$ $\approx 1.5)$.

The selected concentrations of metals in the initial solution, as well as the concentration of P507 and the degree of its saponification, correspond to almost complete loading of the extractant and are similar to the parameters applied at the separation cascades.

\section{Calculation of standard physico-chemical parameters at a joint extraction of ndand pr by p507 from chloride medium}

$100 \mathrm{ml}$ of $33 \%$ saponified extractant and $100 \mathrm{ml}$ of joint solution of chlorides of praseodymium and neodymium were loaded into the thermostatic reactor with a magnet stirrer. The temperature was measured by a thermometer with an accuracy of $0.5{ }^{\circ} \mathrm{C}$. This system was thoroughly mixed within 30 minutes at $25^{\circ} \mathrm{C}$. After the complete emulsion separation for 5 minutes, $2 \mathrm{ml}$ of the aqueous phase was taken for analysis. The concentration of $\mathrm{Pr}^{3+}$ and $\mathrm{Nd}^{3+}$ in the sample was determined on a spectrophotometer using a calibration graph method. The concentration of $\mathrm{H}^{+}$in the sample was determined by the acid-base method of titration by the solution of $0.015 \mathrm{M} \mathrm{NaOH}$ using a "methyl orange" indicator. The experiment was repeated several times until reaching $60^{\circ} \mathrm{C}$ in increments of $5{ }^{\circ} \mathrm{C}$. A total of seven experimental results were described.

The concentration of $\mathrm{Pr}^{3+}$ and $\mathrm{Nd}^{3+}$ in the organic phase was calculated by solving the equation of material balance (eq. 1). Then it was used for the calculation of the distribution of the ratio (D) of the corresponding component according to Equation 2.

$$
\underline{C_{\text {org }}}=C_{\text {init }}-C_{A q}
$$

where $C_{\text {org }}$ is the component concentration in the organic phase, $\mathrm{mol} / \mathrm{dm}^{3} ; C_{\text {init }}$ is the component concentration in the initial solution, $\mathrm{mol} / \mathrm{dm}^{3} ; C_{A q}$ is the component concentration in the raffinate, $\mathrm{mol} / \mathrm{dm}^{3}$.

$$
D=\frac{C_{O R G}}{C_{A Q}}
$$

where $\mathrm{D}$ is the component distribution ratio

The change in the volume ratio due to sampling was taken into account when calculating D. The material balance of both metals was controlled at each experimental point.

P507 exists as a dimer when diluted with non-polar solvents[17]. This phenomenon can be described according toEquation3:

$$
2 \underline{H A} \rightarrow \underline{H_{2} A_{2}}
$$

where $\mathrm{H}_{2} \mathrm{~A}_{2}$ is a dimer of 2-ethylhexyl phosphonic acid mono-2-ethylhexyl ether (P507). 
The cation exchange according to Equation 4 takes place when rare earths metals ions are extracted by P507 [10].

$$
\mathrm{Ln}^{3+}+\underline{3 \mathrm{H}_{2} \mathrm{~A}_{2}} \rightarrow \underline{\operatorname{Ln}\left(\mathrm{HA}_{2}\right)_{3}}+3 \mathrm{H}^{+}
$$

where $\mathrm{Ln}^{3+}$ - the cations of rare earths metal;

Taking into account Equation 3 and Equation 4, the equilibrium concentration of the dimer P507 can be calculated by eq.(5)

$$
\underline{\left[H_{2} A_{2}\right]}=\frac{C_{P 507}}{2}-3 \cdot\left(\underline{C_{P r}}+\underline{C_{N d}}\right)
$$

where $C_{P 507}$ is the concentration of the monomer of P507 in the initial extractant, $\mathrm{mol} / \mathrm{dm}^{3} ;\left[\mathrm{H}_{2} \mathrm{~A}_{2}\right]$ is the concentration of the dimer of P507 under the equilibrium conditions, $\mathrm{mol} / \mathrm{dm}^{3}$.

The extraction concentration constant $(\mathrm{K})$ for Equation 4 can be written in the form (6). Formula (6) can be transformed to (7) taking into account $D=\frac{\left[\operatorname{Ln}\left(\mathrm{HA}_{2}\right)_{3}\right]}{\left[\mathrm{Ln}^{3+}\right]}$. The extraction constant was calculated at different temperatures at all experimental points. The values of the extraction constants were used to calculate the changes in the Gibbs free energy $\left(\Delta \mathrm{G}_{\exp }\right)$ according to Equation 8 .

$$
K_{E x}=\frac{\left[L n\left(H A_{2}\right)_{3}\right] \cdot\left[H^{+}\right]^{3}}{\underline{\underline{\left[H_{2} A_{2}\right]^{3}} \cdot\left[L n^{3+}\right]}}
$$

Where $K_{E x}$ is the extraction concentration constant; $\left[\mathrm{Ln}^{3+}\right]$ is the equilibrium component concentration in the raffinate, $\mathrm{mol} / \mathrm{dm}^{3} ;\left[\operatorname{Ln}\left(\mathrm{HA}_{2}\right)_{3}\right]$ is the equilibrium component concentration in the extract, $\mathrm{mol} / \mathrm{dm}^{3} ;\left[H^{+}\right]$is the equilibrium concentration of protons in the raffinate, $\mathrm{mol} / \mathrm{dm}^{3}$;

$$
\begin{aligned}
& K_{E x}=D \cdot \frac{\left[H^{+}\right]^{3}}{\frac{\left[H_{2} A_{2}\right]^{3}}{2}} \\
& \Delta G_{\text {exp }}=-R T \ln \ln K_{E x}
\end{aligned}
$$

where $\Delta \mathrm{G}_{\text {exp }}$ are the changes in Gibbs free energy, based on the experimental data, $\mathrm{J} / \mathrm{mol}$; $\mathrm{R}$ is the universal gas constant, $\mathrm{J} /(\mathrm{mol} \cdot \mathrm{K}) ; \mathrm{T}$ - the temperature in the reactor, $\mathrm{K}$.

Changes in the Gibbs free energy are associated with standard physicochemical values: the change in enthalpy $(\Delta \mathrm{H})$ and entropy $(\Delta \mathrm{S})$, according to Equation9, which is called the Gibbs-Helmholtz equation.

$$
\Delta G_{\text {calc }}=\Delta H-T \cdot \Delta S
$$

Where $\Delta \mathrm{G}_{\text {calc }}$ are the changes in the Gibbs free energy obtained during the calculation, $\mathrm{J} / \mathrm{mol} ; \Delta \mathrm{H}$ is the change in enthalpy, $\mathrm{J} / \mathrm{mol} ; \Delta \mathrm{S}$ is the change in entropy, $\mathrm{J} /(\mathrm{mol} \cdot \mathrm{K})$.

The values of changes in enthalpy $(\Delta \mathrm{H})$ andentropy $(\Delta \mathrm{S})$ were calculated using the Gibbs-Helmholtz equation from changes in the Gibbs free energy $\left(\Delta \mathrm{G}_{\text {calc }}\right)$ in the range $15-$ $60{ }^{\circ} \mathrm{C}$, by solving a system of equations including Equation 9 which are written at each experimental value of $\mathrm{K}$. This problem was solved by finding the global minima of the target function calculated using the difference between the experimental $\left(\Delta \mathrm{G}_{\text {exp }}\right)$ and calculated $\left(\Delta \mathrm{G}_{\text {calc }}\right)$ values of the Gibbs free energy changes. The $\Delta \mathrm{H}$ and $\Delta \mathrm{S}$ values of $\operatorname{Pr}$ and $\mathrm{Nd}$ were used as independent variables to find the minima of the target function. The calculation results are presented in the form of a graph in Fig. 1. The calculated values $\Delta \mathrm{G}_{\text {calc }}$ are well consistent with the experimental data within the experimental accuracy determined by the accuracy of concentrations of metals and $\mathrm{H}^{+}$, which is determined at about $5 \%$. 


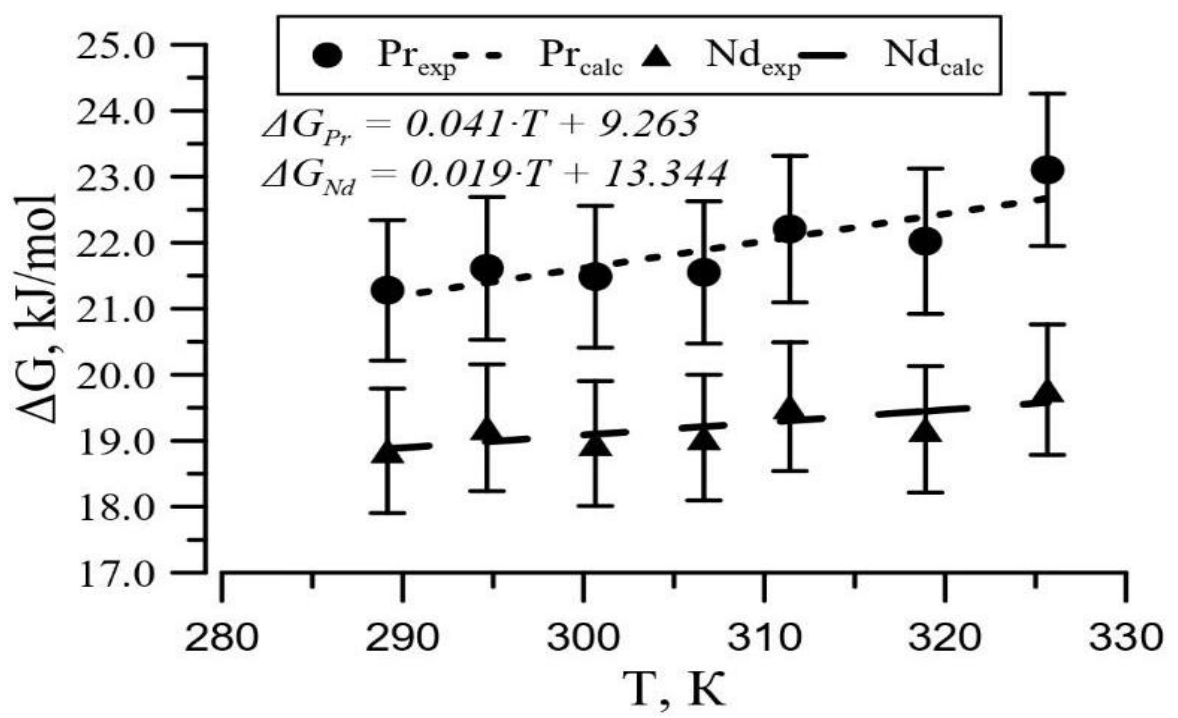

Fig. 1.Temperature dependence of changes in the Gibbs free energy at a joint extraction of $\mathrm{Nd}$ and $\mathrm{Pr}$ by $\mathrm{P} 507$ from chloride medium at the range of $15-60{ }^{\circ} \mathrm{C}$.

The table shows the values of the changes in enthalpy $(\Delta \mathrm{H})$ and entropy $(\Delta \mathrm{S})$, and average values of changes in the Gibbs free energy for reaction (4) in the range $15-60{ }^{\circ} \mathrm{C}$.

The reaction (4) is endothermic. This is consistent with data from other researchers, for example [18]. The difference in the values of $\Delta \mathrm{G}$ between $\operatorname{Pr}$ and $\mathrm{Nd}$ is about $15 \%$. It reflects the established equilibrium, which is described by reaction (4) as unequal extraction of $\mathrm{Pr}$ and $\mathrm{Nd}$. The slope of the temperature dependence of the change in the Gibbs free energy for $\mathrm{Pr}$ is almost 2 times greater than for $\mathrm{Nd}$. This allows us to expect a better separation of elements at a higher temperature. Herewith, the extraction of $\operatorname{Pr}$ is less endothermic, but this leads to a larger increase in total entropy. When the extraction system is forced out from the equilibrium state, the interfacial transfer of praseodymium will be easier since it will require less heat, but the transfer of neodymium is beneficial in terms of reducing the total energy of the system. In this system, it is possible to select the conditions under which the transfer of neodymium from one of the phases will be delayed in relation to praseodymium. Concentrations will change asynchronously, and a new equilibrium state will not be reached for the various components simultaneously. In this case, one can expect a depletion or enrichment of one of the phases relative to the initial equilibrium state.

Table 1. Values of the changes in enthalpy $(\Delta \mathrm{H})$ and entropy $(\Delta \mathrm{S})$, and average values of changes in the Gibbs free energy for the joint extraction of $\mathrm{Nd}$ and Prby P507 in the range of $15-60{ }^{\circ} \mathrm{C}$.

\begin{tabular}{|c|c|c|c|}
\hline Metal & $\Delta \mathrm{G}, \mathrm{kJ} / \mathrm{mol}$ & $\Delta \mathrm{H}, \mathrm{kJ} / \mathrm{mol}$ & $\Delta \mathrm{S}, \mathrm{J} /(\mathrm{mol} \cdot \mathrm{K})$ \\
\hline $\operatorname{Pr}$ & & $\begin{array}{c}21.9 \pm 1.1 \\
-41.2 \pm 2.1\end{array}$ & $9.3 \pm 0.5$ \\
\hline $\mathrm{Nd}$ & & $\begin{aligned} & 19.2 \pm 1.0 \\
& 19.1 \pm 1.0\end{aligned}$ & $13.3 \pm 0.7$ \\
\hline
\end{tabular}

\section{The automatic set-up for investigation of liquid extraction under dynamic regime conditions}

To study the distribution of components under external influence onto the extraction system, an experimental installation was built. This allows monitoring the influence on the 
extraction of the metal of oscillation changes in physico-chemical parameters in the reactor in a "real-time" mode. The scheme of the set-up is shown in Fig. 2.

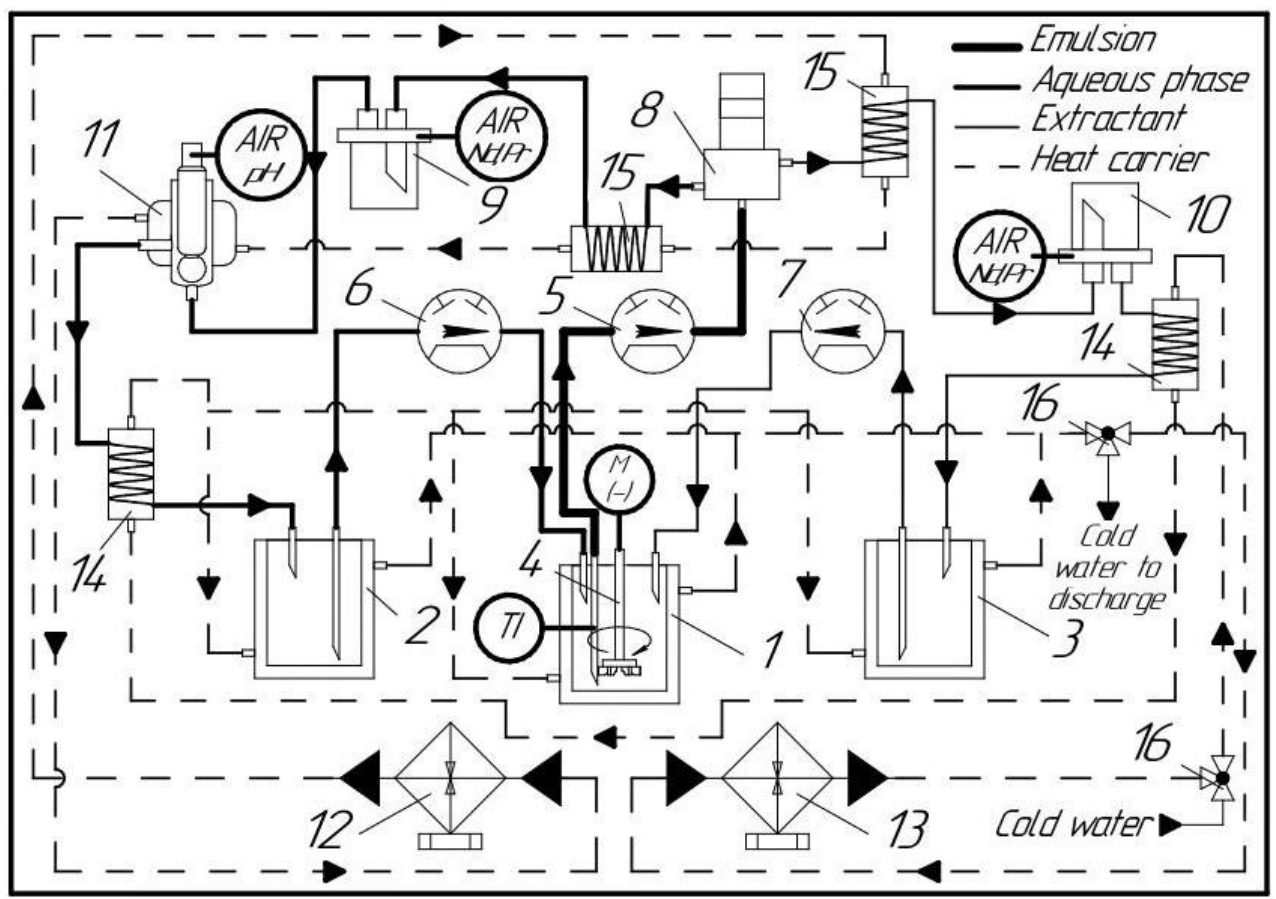

Fig. 2. The schematic diagram of an automatic set-up for investigation of liquid extraction under dynamic conditions.

Where 1: the reactor with jacket; 2,3 : tanks with jacket for aqueous and organic phases; 4: the mechanical stirrer of Rusredmet; 5: peristaltic pump for emulsion»; 6,7: the peristaltic pumps for aqueous and organic phases; 8: the centrifugal extractor «EC-33 NIKIMT»; 9,10: flow cell of a spectrophotometer for aqueous and organic phases analysis; 11: the flow cell for measuring $\mathrm{pH}$; 12: the thermostat for cooling flows; 13: the thermostat for the heating system in the reactor; 14, 15: $100 \mathrm{~mm}$ coil heat exchanger; 16: three-way valve "L-type"; TIR: temperature recording unit; AIR: potentiometer Thermo Orion 720p / one single ray automatic spectrophotometer SF-2000 OKB Spectr.

The installation includes 3 tanks with jackets, 2 mechanical stirrers with the possibility of changing the rotation speed, 2 thermostats, 2 three-way valves, 3 peristaltic pumps, centrifugal extractor, 2 spectrophotometers, $\mathrm{pH}$-meter and cell for measuring $\mathrm{pH}$, temperature recording unit, 3 personal computers for receiving data from sensors and devices.

Using two peristaltic pumps 6 and 7, the aqueous and organic phases from tanks 2 and 3 are pumped to reactor 1 , where they are mixed using a turbine stirrer 4 . The emulsion is pumped for separation into separator 8 using a peristaltic pump 5. The flows of the aqueous and organic phases leave the separator and, passing through heat exchangers 15 , fall into the flow cell of automatic spectrophotometers 9 and 10, respectively. Then the aqueous phase flows to the flow cell for measuring $\mathrm{pH} \mathrm{11,} \mathrm{after} \mathrm{which} \mathrm{it} \mathrm{enters} \mathrm{the} \mathrm{tank} \mathrm{for} \mathrm{the}$ accumulation of the aqueous phase 2, passing through heater 14. The flow of the organic phase enters tank 3, passing through heater 14, immediately after leaving the spectrophotometer cell. 
Thermostat 12 maintains a constant temperature at $25^{\circ} \mathrm{C}$ to get spectra and measure $\mathrm{pH}$ in the organic and aqueous phases. To change the temperature in the reactor flows of cold water from the cold water tap and warm water from the thermostat 13 are alternately directed into the jacket, using three-way valves 16 .

All technological parameters: concentrations of metals in the raffinate and extract flows, acidity in the raffinate flow, and temperature in the reactor are measured automatically every 5 seconds and recorded to the appropriate files on PC. The concentrations of metals are calculated using the calibration graph method. The accuracy of measurements is less than $10 \%$.

\section{$5 \quad$ Studying of influence of cyclic changes the temperature in a reactor on the extraction system}

The behavior of the extraction system during the changing of the stirring intensity and the rate of heating or cooling of the emulsion was studied.

The result of the experiment, in which an increase in $\beta_{\frac{N d}{P r}}$ was registered under the action of temperature on the equilibrium extraction system, is shown in Fig. 3. In this case, a simplified version of the installation with one spectrophotometer only for analysis of the aqueous phase was used. The organic phase entered the appropriate tank immediately after leaving the separator. The rate of the heating and subsequent cooling in the range of $25-65$ ${ }^{\circ} \mathrm{C}$ was about 15 minutes.

The results of the experiment on a more complicated version of the installation with the measurement of the concentration of the metals in both phases are shown in Fig. 4. During the experiments, the cooling and the heating rate were faster than in the first run. The time of heating or cooling was reduced to 3-5 minutes.

According to the proposed assumption, greater separation can be achieved with lower stirring intensity and a high heating or cooling rate.

In this experiment the conditions were found under which an increase or decrease of the separation factor of $\mathrm{Nd} / \mathrm{Pr}$ pair is associated primarily with the controlled transfer of praseodymium. Here, the concentration of neodymium remains almost constant during the experiment time. As in the first run, praseodymium is stripped from the organic phase upon cooling of the system with preliminary heating, but only to a certain level. It may be noticed that at some point, the transfer of not only praseodymium, but also neodymium begins. The separation factor begins to decrease at this point. 


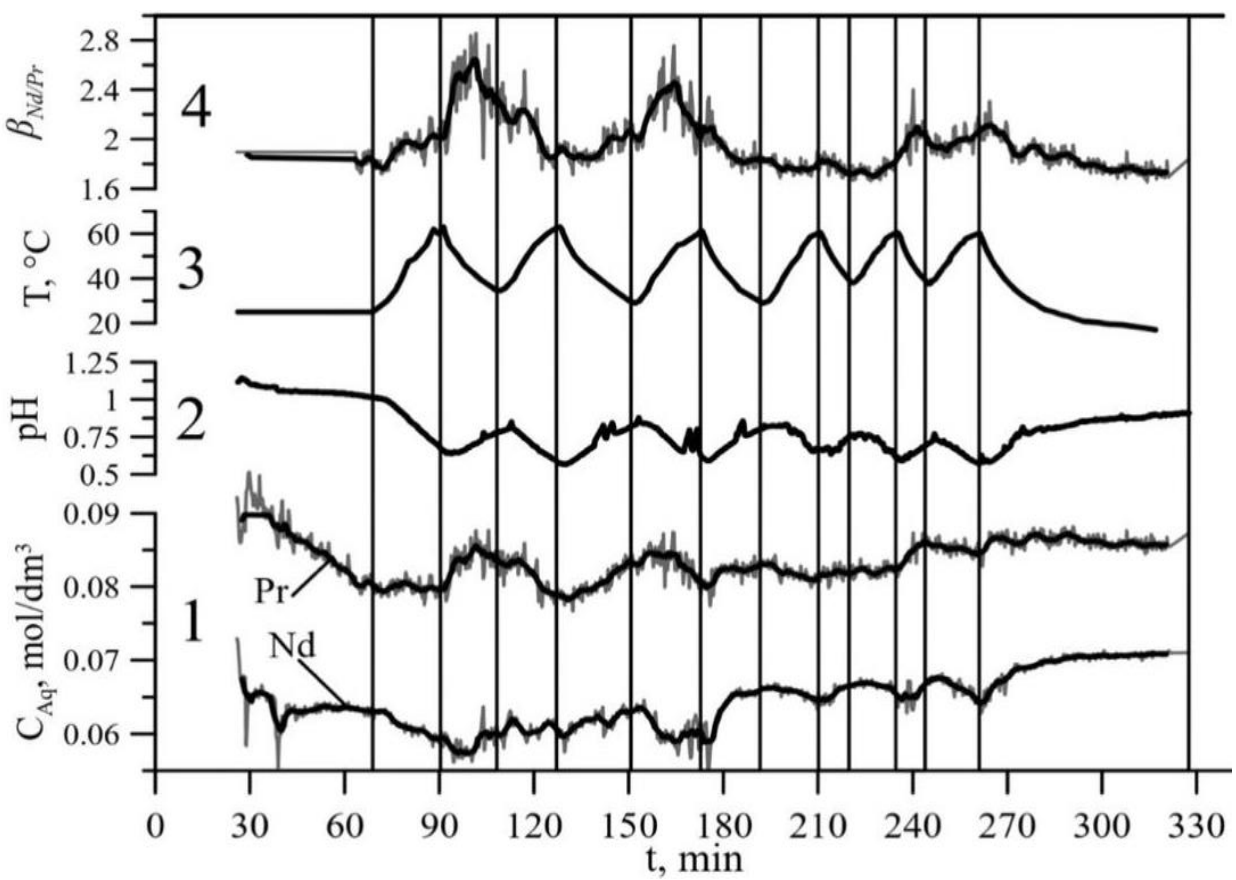

Fig. 3. The first temperature experiment. Time profiles of the main parameters of the system during a cyclic change in the temperature in the reactor: 1 : the concentration of $\mathrm{Nd}$ and $\mathrm{Pr}$ in the aqueous phase, 2: the $\mathrm{pH}, 3$ : the temperature in reactor, 4: the separation factor of $\mathrm{Nd} / \mathrm{Pr}$ pair.

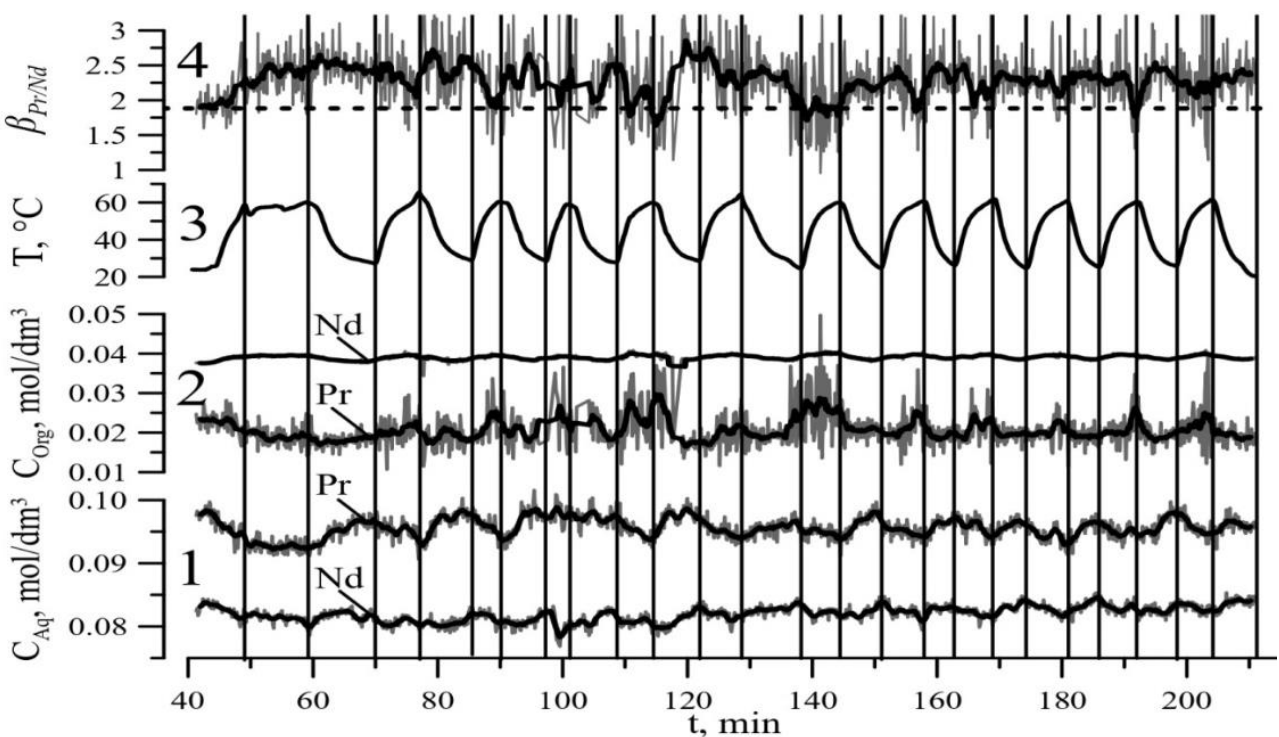

Fig. 4. The second temperature experiment. Time profiles of the main parameters of the system during a cyclic change in temperature in the reactor: 1: the concentration of $\mathrm{Nd}$ and $\mathrm{Pr}$ in the aqueous phase, 2: the concentration of $\mathrm{Nd}$ and $\mathrm{Pr}$ in the organic phase, 3: the temperature in reactor, 4: the separation factor of $\mathrm{Nd} / \mathrm{Pr}$ pair. 
It was registered multiple increases of $\beta_{\frac{N d}{P r}}$ equal approximately to 2.6. On the fourth graph in Figure 4, a dotted line indicates the separation factor under the equilibrium conditions at $60{ }^{\circ} \mathrm{C}$.

It is shown that with an oscillation change in temperature in the reactor with an amplitude and frequency at which stripping of the well-extracted component does not occur, it is possible to achieve high separation of elements under nonstationary conditions.

\section{Studying of influence of cyclic change in ph of an aqueous phase on the extraction system}

To study the effect of oscillation changes in the $\mathrm{pH}$ of the aqueous phase on the separation of the $\mathrm{Nd} / \mathrm{Pr}$ pair, a series of experiments were carried out, similar to those described in the previous paragraph. The temperature remained constant around $35^{\circ} \mathrm{C}$. After the system had achieved an equilibrium, the $\mathrm{pH}$ value became equal to about 0.8 . The organic phase was poured into the appropriate tank; the $\mathrm{pH}$ of the aqueous phase was adjusted to value 1.8 using $12 \mathrm{M} \mathrm{NaOH}$. After this, the supply of extractant was resumed: the $\mathrm{pH}$ decreased to 1.5. Subsequently, the acid was added without phase separation, but the addition of alkali required phase separation and a pause in the operation of the installation. Several milliliters of $12 \mathrm{M} \mathrm{HCl}$ or $12 \mathrm{M} \mathrm{NaOH}$ were added to the aqueous phase tank and stirred at high speed. The extraction progress was monitored using a $\mathrm{pH}$-meter and spectrophotometers. When the decrease or increase in $\mathrm{pH}$ ceased, alkali or acid, respectively, was added to the aqueous phase, as previously described.

The extraction system was shifted from equilibrium state by alternately adding $4 \mathrm{ml}$ of acid and alkali in the first experiment, and from 1 to $3 \mathrm{ml}$ in the second experiment.This run was carried out within 2 days. The experiment results are separated into two parts and shown in Fig.5 and 6.

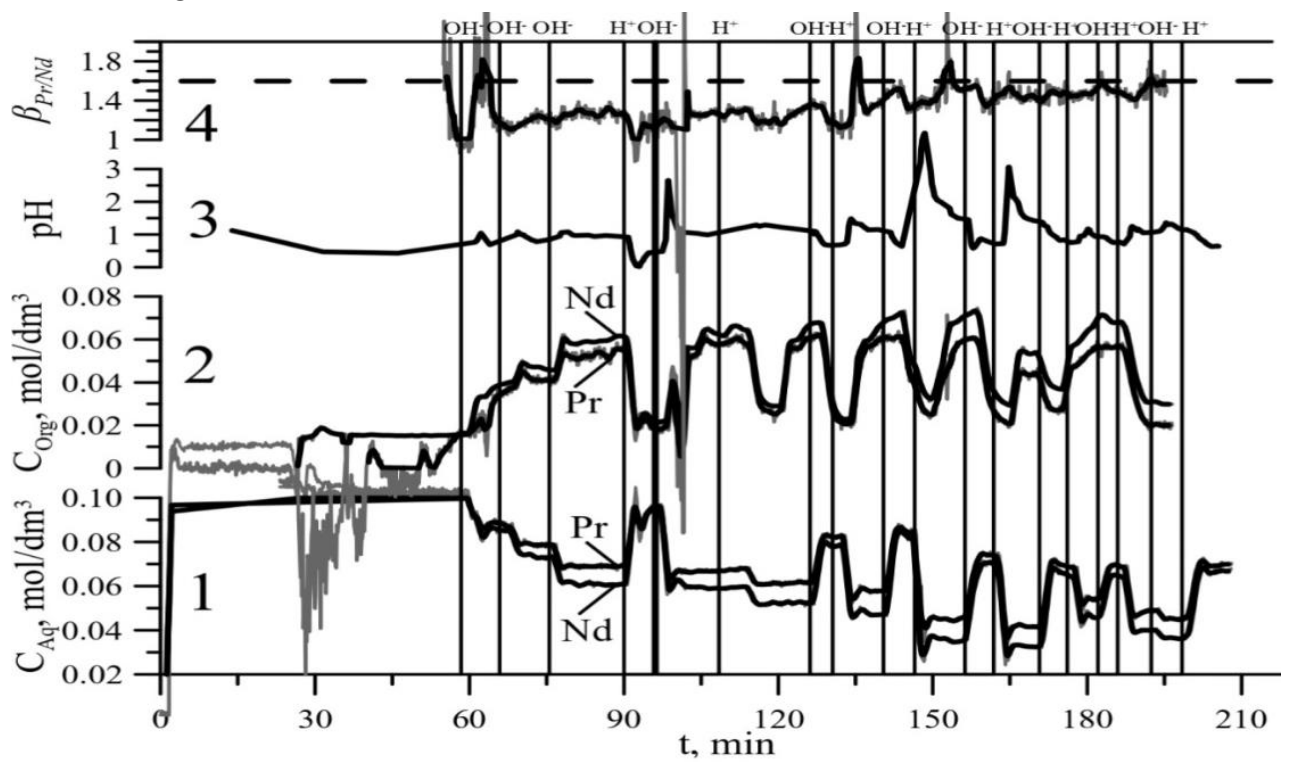

Fig. 5. The first $\mathrm{pH}$ experiment. Time profiles of the main parameters of the system during a cyclic change in $\mathrm{pH}$ : 1: the concentration of $\mathrm{Nd}$ and $\mathrm{Pr}$ in the aqueous phase, 2: the concentration of $\mathrm{Nd}$ and $\mathrm{Pr}$ in the organic phase, 3: the $\mathrm{pH}$ in the raffinate, 4: the separation factor of $\mathrm{Nd} / \mathrm{Pr}$ pair. 
With the addition of acid, the $\mathrm{pH}$ dropped to a minimum of 0.2 , it has been found that at $\mathrm{pH}=0.5$ the metals are fully stripped. While the organic and aqueous phases were in contact, the increase of $\mathrm{pH}$ was limited to 1.5 . Further increase of aqueous phase $\mathrm{pH}$ caused the formation of precipitates in the extract. It was impossible to increase the $\mathrm{pH}$ more than to the value equal to 1.8 .

It is assumed that with the addition of acid, stripping the less extractable component should occur first, and with the addition of alkali, the well-extractable component extraction should occur. The alternate addition of acid or alkali to the system can lead to the accumulation of this effect and increase separation.

On Figures 5 and 6 , it is well seen that a new state in the extraction system is established within 30 seconds after the addition of acid or alkali. In this case, at first, the concentrations of both metals in the aqueous and organic phases synchronously change to the same value, after which each of them reaches its equilibrium value. Neither in the case of adding small amounts of acid or alkali nor in the case of large amounts, no separation factor change was registered. On the fourth graph in Figures 5 and 6, a dotted line indicates the separation factor under the equilibrium conditions at $30^{\circ} \mathrm{C}$. The predominant extraction or stripping of one of the components was not observed. Besides, the value of the separation factor decreases sharply when the $\mathrm{pH}$ changes, and then slowly returns to the equilibrium value of $1.5-1.6$. In Figures 4 and 5 , a blue line indicates this value.

Changes in the $\mathrm{pH}$ of the raffinate allow to change the total metals content in the phases, but it does not allow separating the metals selectively.

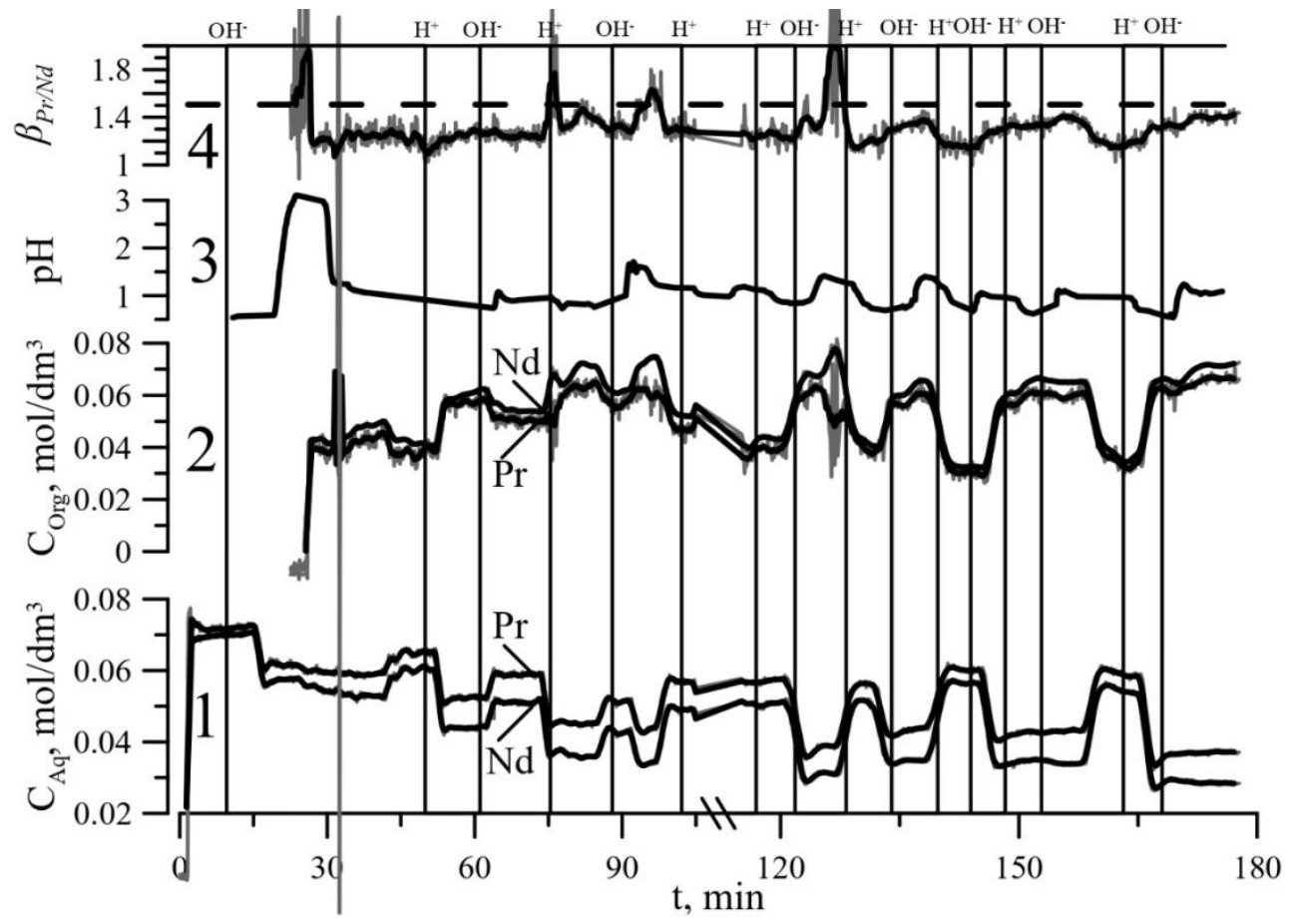

Fig. 6. The second $\mathrm{pH}$ experiment. Time profiles of the main parameters of the system during a cyclic change in $\mathrm{pH}$ : 1: the concentration of $\mathrm{Nd}$ and $\mathrm{Pr}$ in the aqueous phase, 2: the concentration of $\mathrm{Nd}$ and $\mathrm{Pr}$ in the organic phase, 3: the $\mathrm{pH}$ in the raffinate, 4: the separation factor of $\mathrm{Nd} / \mathrm{Pr}$ pair.

With an increase in $\mathrm{pH}$ (alkali addition), the equilibrium of reaction (4) shifts toward the formation of an extractible form. First, the binding of P507 molecules occurs with both metals, and only after this stage, the less extracted metal will be displaced back into the 
raffinate due to the distribution of the well-extracted metal. When acid is added, as described earlier, the joint stripping of both components occurs to a certain level, after which the metals are distributed in accordance with the stability of their complexes with the extractant.

A metal separation mode, based on fast extraction of a less extractable component at the first moment of nonstationary extraction, may be proposed. If, after the addition of the alkali, the phases are separated at a moment when the capacity of the extractant is not fully exhausted, the extractant will be oversaturated with the less extracted component. At the following contact of this extractant with the aqueous solution, a larger amount of less extracted component will be displaced into the raffinate than during the standard countercurrent process. However, experimentally, as part of this work, the assumption has not been verified.

\section{$7 \quad$ Conclusions}

The values of the extraction constant $\left(\mathrm{K}_{\mathrm{Ex}}\right)$ in the range of $15-60{ }^{\circ} \mathrm{C}$ were calculated from experimental data for joint extraction of $\mathrm{Nd}$ and Pr with the extractant based on P507 from chloride media. The values of the changes in enthalpy $(\Delta H)$ and entropy $(\Delta S)$ were calculated for each metal from the temperature dependence of the extraction constant.

It was shown, that with oscillation change in temperature in the reactor a periodic increase in the separation factor $\beta_{\frac{N d}{P r}}$ to $2.6 \pm 0.1$ was achieved. This effect is possible if the extraction system heats up or cools faster than the state of thermodynamic equilibrium is established.

With oscillation change in the acidity of the aqueous phase, the effect of an increase in the separation factor is not achieved;with the addition of acid or alkali, a decrease in $\beta_{\frac{N d}{P r}}<$ 1.0 and subsequent return of the system to equilibrium state to $\beta_{\frac{N d}{P r}}=1.6 \pm 0.1$ occurred.

Based on the observed phenomena, an effective mode for extraction separation of rare earths metals has been created.

The authors appreciate the different kind of support of the project and assistance in creating the set-up of the engineering center of chemical technology "Rusredmet" and then the staff and masters of glass workshop of Saint-Petersburg State Institute of Technology for their high skills demonstrated in the manufacture of unique parts of the experimental set-up.The Ministry of Education and Science of the Russian Federation supported the research (state task 0785.00.X6019).

\section{References}

1. F.Z. Xie, A critical review on solvent extraction of rare earth metals from aqueous solutions, Minerals Engineering, 56, 10-28 (2014)

2. J.Z. Zhang, Separation hydrometallurgy of rare earth elements. (Switzerland: Springer International Publishing, 2016)

3. E.G. Polyakov, Rare earth metallurgy. (Moscow: Metallurgist, 2018)

4. I.B. Sergeyev, Incentives for the creation of the competitive rare-earth industry in Russia in the context of global market competition, Journal of Mining Institute, 211, 104-116 (2015) 
5. T.L. Litvinova, Complex processing of phosphogypsum-A way of recycling dumps with reception of commodity production of wide application, Journal of Ecological Engineering, 19(2), 221-225(2018)

6. O.S. Cheremisina, Specific features of solvent extraction of REM from phosphoric acid solutions with DEHPA, Mineral Processing and Extractive Metallurgy, 1-7 (2019)

7. V.C. Sergeyev, Kinetics Study of Solvent and Solid-Phase Extraction of Rare Earth Metals with Di-2-Ethylhexyl Phosphoric Acid, Metals 10(5), 687 (2020)

8. D.A. Alferova, Concentration and Separation of Heavy Rare-Earth Metals at Stripping Stage, Metals, 9(12). 1317 (2019)

9. A.T. Fedorov, Study of iron stripping from D2EHPA solutions during the process of rare earth metals extraction from phosphoric acid, ARPN Journal of Engineering and Applied Science, 8(1), 1591-1595 (2019)

10. V. Agarwal, Solvent extraction and separation of cerium (III) and samarium (III) from mixed rare earth solutions using PC88A, Minerals \& Metallurgical Processing 34(3), 125-131 (2017)

11. C.K. Asnani, USA Patent No. 10,227,676 (2019)

12. Innovation Metals, Retrieved from Website of Innovation Metals company: http://www.innovationmetals.com/the-rapidsx-process/ (2020)

13. S. M. Murakami, Extraction of Pr (III), Nd (III), and Dy (III) from HTFSA aqueous solution by TODGA/phosphonium-based ionic liquids, Solvent Extraction and Ion Exchange, 34(2), 172-187 (2016)

14. E.A. Shevchenko, Joint mass transfer of two components associated with the spontaneous interfacial convection in the liquid-liquid extraction system, Chemical Engineering Science 195, 301-311 (2019)

15. E.K. Golubina, Intensification of the extraction of rare earth elements at the local mechanical vibration in the interfacial layer, Chemical Engineering and ProcessingProcess Intensification, 132, 98-104 (2018)

16. A.A. Kopyrin, New methodological approach to investigation of kinetics of REE extraction in nonstationary conditions, Journal of Rare Earths, 25(4), 385-391 (2007)

17. Y.O. Mori, Extraction equilibrium of Ce (III), Pr (III) and Nd (III) with acidic organophosphorus extractants, Journal of chemical engineering of Japan, 21(1), 86-91 (1988)

18. Y.L. Xiong, Kinetics and Mechanism of $\mathrm{Yb}$ (III) Extraction and Separation from $\mathrm{Y}$ (III) with Mixtures of bis (2, 4, 4-trimethylpentyl) phosphinic acid and2-ethylhexyl phosphonic acid mono-2-ethylhexyl ester, Separation Science and Technology, 41(1), 167-178 (2006) 